\title{
Stress Factors and the Teaching Performance of the College Faculty
}

\author{
Julieta Remedios Betonio
}

\begin{abstract}
This study aimed to determine the level of stress the college faculty experienced in terms of Work related, Peer related, Family related, Economic related, Schools' Policies related and Management Practices related stresses. It also looked into the level of effectiveness of the faculty in their teaching performance in terms of Classroom Management, Communication skills, Facilitating Students learning, evaluation and Teacher Student relationship. The respondents of the study were the full-time college faculty who were teaching at La Salle University in SY 2012-2013. It is a descriptive research study and the data were gathered using a standardized questionnaire. The data gathered were analyzed, and interpreted through Weighted Mean and Rank. Results of the study showed that the faculty experienced moderate level of stress in the areas of Economic related stress, Schools' Policies and Management Practices stresses and experienced low level of stress with Work and Peer related stresses. Most of the faculty claimed they experienced very low level of stress with Family. The overall rating of the effectiveness of the performance of the faculty in all parameters were very satisfactory which means there is still room for improvement to make it an outstanding assessment in the future.
\end{abstract}

Index Terms-Stress, effectiveness, teaching performance.

\section{INTRODUCTION}

Education industry is one of the business organizations that offer services in terms of molding and crafting youngsters into good citizens of the country. It is the kind of business where individuals learned good values and various techniques and strategies that they can use as they start their own personal endeavor in life. These values, techniques and strategies are usually imparted to the students in all educational institutions through teaching methods that every teacher uses when conducting the lessons. Teaching is a very challenging job in which the teachers' performance is wrapped up in her/his personality. It requires a unique talent and sense of vocation if the teacher has to perform her/his role exceptionally well.

According to Hemphil as cited by [1], a very good teaching performance usually results when one teaches with enthusiasm, competence, effectiveness and with dedication to the profession. The teacher has to do dual tasks. One is instilling knowledge and the other one is breaking down the barriers that blocked during the process of inculcating such knowledge. Such concerns demands that those teaching thestudents must be creative and practice it diligently and faithfully. It is a mere fact that teachers are one of the key

Manuscript is received March 4, 2014; revised May 20, 2014.

Julieta Remedios Betonio is with the College Faculty of La Salle University, Ozamiz City (e-mail: julietabetonio@yahoomail.com.ph). factors in the teaching-learning process. They perform a very vital role in molding the youth for the good of their family, community, and the entire society [2]. They are also sometimes like candles that light the path of other individuals and they are happy to be instrumental in other's success, especially that of their students as pointed out by Lardizabal in [3].

Like any other professional endeavors, those in the teaching career have a wider scope of social responsibilities to take care of. The society alone, has always anticipated a lot from the teachers such as to serve a large population as second parents dealing with the emotional tangles and torments of adolescent stage of the youth entrusted to their care. Faced with this scenario, some teachers can tire of catering to individual needs and at the same time striving for professional excellence. Along this line, [4], commented that teachers often feel that they are under stress or burn out, that directly affect their teaching performance. Generally stress is the adverse reaction of every individual person who happens to experience so much pressure and other types of demand of workload placed upon his/her ability to adapt it. It is also referred to as a normal physical response to events in life that makes you feel threatened or distort your equilibrium. On one hand, stress is not always bad. In small doses, it can help the person to perform under pressure and motivate him to do best, [5]. This was affirmed by [6], when he said that stress is part of life's challenges that all persons must face. A certain degree of stress is unavoidable as a matter of fact an acceptable level can serve as a challenge to improve the teachers' efficiency. But on other side, if the level of stress is such that the teacher will not be able to satisfactorily handle it, the result of teachers' efficiency may be negative. In the same vein, another researcher claimed that stress is what keeps you alert and alive to tackle your responsibilities during presentation at work, sharpens your concentration and even compels you to reach your target. However, if it is already beyond stipulated boundaries, stress will stop being helpful and begin to cause major damage to health, mood, relationships, efficiency and then productivity as well as the standard quality of your life, [5].

From experiences, the researcher has also been exposed to stress and been teaching for a number of years in this institution and has observed the different effects of stress from colleagues. With this, the researcher would like to look into the level of stress and the teaching performance of the faculty and hope that from the output the researcher will be able to come up with ideas/strategies on how to handle stressors in ones' work or workplace and share them to her colleagues thru a forum or seminar.

\section{A. The Problem}

The study aims to determine the relationship of the level of 
stress to the teaching performance of the college faculty. Specifically, it seeks to address the following questions: 1) What is the level of stresses experienced by the faculty member in terms of the following dimensions; Work-related stress, Family-related stress, Peer-related stress, Economic-related stress, School Policies-related stress and Management Practices-related stress. 2) What is the level of teaching performance of the college faculty members as assessed by the students along the areas of; Classroom, Communication Skills, Facilitating Students Learning, Teaching-Student Relationship and Evaluation. 3) From the result of the study, what interventions may be designed?

\section{B. Significance of the Study}

The result of this study is very important because it will serve as an eye opener to the faculty and administrators that any form of stress one will experience should not be taken for granted and that it could hamper the performance of the faculty if it will not be addressed early. For the HR department, the study could be a good source of information for planning a value system in order to help the faculty members improve their teaching performance. Also, they could develop techniques on how to manage stresses that they may experience by conducting possible continuing training program and stress management seminars. For the Administrators, it would aid them in assessing the strengths and weaknesses of the faculty and they could provide insights in formulating policies to upgrade the teaching performance of the faculty. Faculty: The results would help them truly identify their weak and strong points thereby find ways and means to improve their weaknesses and capitalize their strengths in order to enhance their teaching methods and techniques. Students on one hand, since they are the recipients of the evaluative process, the efficiency and effectiveness of the teaching performance of the faculty would improve the students' academic performance.

\section{METHOD}

Descriptive research survey was used in this study. It was conducted at La Salle University, Ozamiz City. The level of stresses experienced by the faculty was in terms of Work-related stress, Family-related stress, Peer-related stress, Economic-related stress, School Policies-related stress and Management Practices-related stress. The level of teaching performance evaluation results- Second Semester, SY-2012-2013 of the college faculty was used and it was taken from the Institutional Evaluation Office of La Salle University.

\section{A. Research Respondents}

The respondents were the full-time faculty members who were currently teaching in the second semester of SY 2012-2013. The study was conducted in the college department only covering all the various colleges/units of $\mathrm{La}$ Salle University

\section{B. Research Instruments}

The study conducted was a descriptive study. A standardized questionnaire was the principal tool in data gathering of the study. It established the level of stress and the teaching performance of the faculty who were teaching in the second semester-SY 2012-2013. The standardized questionnaire was adapted from Dizon, 2005.

\section{Statistical Treatment of Data}

After collecting the deployed questionnaires from the various colleges/units of La Salle University, the data were tallied, analyzed and interpreted using Weighted Mean and Rank. The following are the interpretation of the scores of the level of stress with the hypothetical mean range.

$\begin{array}{ccl}\text { Scale } & \begin{array}{c}\text { Hypothetical Mean } \\ \text { Range }\end{array} & \text { Description } \\ 1 & 1.00-1.80 & \text { Very Low } \\ 2 & 1.81-2.60 & \text { Low } \\ 3 & 2.61-3.40 & \text { Moderate } \\ 4 & 3.41-4.20 & \text { High } \\ 5 & 4.21-5.00 & \text { Very High }\end{array}$

\section{Data Gathering Procedure}

The researcher with approval of the Deans and the kind assistance of their secretaries of the different colleges/units of La Salle University distributed the questionnaires and collected them after three days. The data from the questionnaires were collated, tallied and interpreted using weighted mean and rank.

\section{PResentation, ANALysis AND INTERPRETAtion OF DATA}

This section presents, analyzes and interprets the data collected in the study which refers to the different stress factors and the level of the teaching performance of the college faculty.

Work related stress is the result of a conflict between the roles and needs of an individual employee and the demands of the workplace or when the skills and capabilities of the subordinates do not match with the job assigned to him. The study discloses the level of stress the faculty experienced in terms of work, obtained a rating of 2.35 with verbal description of low level. From the result the researcher noticed that in item \#1-"Students are not doing their part in the learning process" got a rating of 2.85 which is equivalent to Moderate. This implies that the faculty experienced stress when performing their assigned task when students do not cooperate. Whereas, the ratings of the rest of the items considered as sources of stress are low. With the overall mean rating of 2.35 for the work related stress, which is equivalent to low level which means the faculty's experience of stress in line with the job they perform is manageable.

In terms of family related stress, the study reveals that the level of stress of the faculty is very low as evidenced by the overall rating of 1.79. Only in item \#3-"I have a lot of household chores to do" which has a high rating of 2.05 but still it is low level, whereas the rest of the indicators range from 1.52 to 1.91 of which the results imply that the level of family related stress of the faculty is very much manageable. This is attributed to the fact that Filipinos have close family ties and that respect and understanding for every member of the family is fostered. 
The overall mean rating of the stress level of faculty with peer is 2.26 which is low level. In this area, the item-"My superior often is not supportive" ranks high with a rating of 2.69 which is moderate. This means that the faculty finds it stressful when their immediate Heads are not supportive of their endeavor/activities. It further implies that there is a need for superiors/immediate Heads to reach out to their teachers so that they will be motivated to perform their tasks. From the interview conducted by the researcher to some faculty, they shared that maybe their superior are too busy that they sometimes forget that their teachers need their attention, time and support too. The good thing that was revealed in this area is that there is no or little competition among peers which is affirmed with a rating of 1.93 with verbal description of low.

Generally, economic stress can be triggered by actual stressful experiences of the person. Loss of job, loss of home and unexpected changes of the family's income and budget could be stressful, [7]. The level of economic related stress of the faculty is moderate with an overall mean rating of 2.61. The rating implies that somehow along this area the stress level of the faculty is apparently felt maybe because of their intentions as stated "I want to uplift my standard of living" that got the highest rating of 3.05, "I have a number of financial obligations/dues to attend" with a rating of 2.83 followed by 2.76 rating for "My take home pay can hardly provide the basic needs of my family" all of which are in moderate levels.

These ratings disclosed that the financial worries of the faculty hails from the fact that their pay is not substantial to meet the basic needs of the family and much more uplift their standard of living which is everybody's dream. Result of the study reveals the overall mean rating of the level of stress of the faculty in terms of School Policies which is 2.97 with verbal description of moderate. High rating of 3.22 is on item "Our school does not have a clear cut policies and standards" so, there is overlapping of responsibilities sometimes. "Our school policies are frequently changed for no good reason at all is 3.12, 3.10 also is on "our school rules and regulations are often changed without prior consultation or notice and 3.06 on "there is an increasing number of co-curricular activities held outside the school which results to conflict with our personal activities. These results showed that the level of stress experienced by the faculty is significant. They are not comfortable whenever the policies are immediately implemented without due consultation from the faculty or when there are changes and it is not disseminated to the faculty before it is implemented. School policies and regulations are crafted by the policy making body of the organization to ensure that employees, suppliers, customers and stakeholders are protected from potential hazards/risks and that it should be supported with appropriate services for the well -being of all employees [8].

The level of stress of the faculty in terms of Management Practices got an overall rating of 2.89 with verbal description of moderate. Rated high among the items under Management Practices is on "There is not enough financial support from the Administration in the course of increasing work load," 3.16 , Informal communication (grapevine communication) is accepted, 3.14 and 3.01 is on "I can't fully communicate my needs to the Administration".

The findings disclosed that these areas are stressors of the faculty and that it could affect their teaching performance if these will not be addressed by the concerned officers. From the interviews conducted by the researcher, the faculty members said that there should be fair application of remuneration to be given to the faculty whenever workload is raised which means compensation should commensurate to the additional workload given. Besides, Communication must be clear-cut too to give everyone the benefit of the doubt and that overlapping of duties and responsibilities must be corrected.

The summary of the overall rating of the level of stresses experienced by the faculty revealed that in general, the level of stresses as experienced by the faculty is still manageable as supported by the rating of 2.48 with verbal description of low. However, three out of the six indicators of the sources or factors of stresses of the faculty were rated moderate. These are along the areas of School's policies, Management practices and Economic related stresses. Therefore, there is need for these factors to be addressed before it could hamper the teaching performance of the faculty.

Every teacher carries big responsibility and every time she performs her job, she/he sees to it that the effort exerted is to the best of his/her ability. He/she has to be sincere, dedicated, knowledgeable, and effective in teaching so that he/she can deliver lessons well to the students. In turn the students will also learn something vital from the lesson. Teaching is a very fulfilling experience. It keeps an individual active and involved and it is even the reason why most teachers who devoted their time to their profession enjoy longer life, [9]. The next discussion is centered on the teaching performance of the faulty.

The results of the study revealed that the faculty of La Salle University's effectiveness in terms of classroom management earned an overall rating of 4.54 with verbal description of Very Satisfactory as rated by the students. This implies that the faculty imposed and objectively observed what the teacher should do while in the classroom.

On the other hand, the level of effectiveness of the faculty in terms of Communication skills revealed that instructors can communicate English confidently. They also speak the language clearly and fluently. The overall rating is 4.56 with verbal description of Very Satisfactory. This implies that the faculty has no difficulties in their communication skills and that they can discuss and elaborate their lessons well.

The effectiveness of Facilitating Students' Learning was rated by the students with 4.46 with verbal description of Very Satisfactory. The results imply that the faculty has mastery of the subject matter that helped them in delivering and imparting their lessons well. It is very important in the sense that it's when the teacher is knowledgeable that the teacher will be able to impart very important and updated information in their own field, [1]. Added to this, from the result it can be gleaned that the teachers presented their lessons in an organized manner that enables the students to understand the lesson. And finally, the voice of the teachers was loud enough to be heard by the entire class thatencourages also the students to participate in the classroom activities.

In terms of evaluation, the effectiveness of the faculty is Very Satisfactory. The teachers were rated by the students 
with an overall rating of 4.48 with verbal description of Very Satisfactory. Result reveals that the faculty constructs test questions that cover the topics which have been discussed in class and that they gave at least three quizzes with a minimum of eighty-five points in a grading period.

The study also disclosed that the level of effectiveness of the faculty in terms of "Teacher-Student relationship" was very satisfactory with a rating of 4.63 . The results implied that there is an established good relationship between the teachers and with their students. It is very important in the sense that, students will be comfortable with their teachers and that whenever they have concerns regarding their subjects or something in line with their chosen courses, they feel free to approach their teachers.

In summary, the result of the study in line with the effectiveness of the teaching performance of the faculty in terms of Classroom Management, Communication Skills, Facilitating Students' Learning, Evaluation and Teacher-Student Relationship showed that the indicator-"Facilitating Students" Learning" obtained the highest rank with a rating of 4.63 which means that the teachers' way of reaching out to the students was appropriate and effective. Hence, they are able to establish camaraderie with students. The rating of Very Satisfactory of all the indicators give the researcher the idea that there is still room for improvement to make it "Outstanding or Excellent" rating in the near future.

\section{SUMmARY OF FINDINGS, CONCLUSION AND RECOMMENDATIONS}

\section{A. Findings}

Majority of the faculty members experienced moderate level of stress in terms of Economic related stress, School Policies, and Management Practices. Low level of stress was experienced by the faculty members in terms of work related stress. However, one of the indicators - "Students are not doing their part in the learning process", was rated Moderate by the faculty. Overall rating of the level of stress in terms of peer related stress was Low but one of the indicators which is "My superior often is not supportive" was rated Moderate by the faculty. Majority of the faculty members experienced Very Low level of stress in terms of Family related stress. The level of effectiveness of the faculty in all parameters of the teaching performance; Classroom Management, Communication Skills, Facilitating Students' Learning, Evaluation and Teacher-Student Relationship were Very Satisfactory. This implied that there is still room for improvement in developing these indicators into "Outstanding/Excellent" assessment.

\section{B. Conclusion}

The researcher distributed and collected the questionnaires through the approval of the Deans and with kind assistance of the Secretaries of the different colleges of the University. In general, the level of stresses experienced by the faculty is manageable with a rating of "low level". Out of six indicators, two areas were rated low level and these are the areas on Work related and Peer related stresses while Family related stress was rated very low level which means that when it comes to family there is not much problems experienced by the faculty simply because by nature Filipinos have close family ties and that every member respects and understands each other. However, three of the six indicators of stresses were rated moderate by the faculty and these are the areas of Economic, School related policies and Management practices related stresses. These stressors should be given due importance and they must be addressed because these will affect the teaching performance of the faculty. On the other hand, the level of effectiveness of the faculty in all parameters of the teaching performance; such as Classroom Management, Communication skills, Facilitating Students' Learning, Evaluation and Teacher-Student Relationship were rated Very Satisfactory.

\section{Recommendations}

Based on the findings and conclusion, the researcher would like to recommend that other researches on similar field but emphasize another variables not covered in this study must be conducted. Furthermore, the Administration must revisit the policies, rules and regulations and address the following areas:

\section{1) Economic related stress}

- Faculty should be given orientation or seminars on how to manage the family resources

- Conduct seminars/symposium on smart money management to help the faculty manage their economic stress and gain control over their financial situation

2) School policies and management practices

- Clearly define the workers' roles and responsibilities.

- Design jobs to provide workers the opportunity to use their skills.

- Policies, rules and regulations must be disseminated and due discussions must be conducted before final implementation.

- Improve Communication lines- reduce uncertainty about development and future employment.

- Give workers opportunities to participate in decision making and actions affecting their jobs.

- Improve interpersonal relationship between Superior and faculty members.

- Faculty must take the initiative to be creative and innovative in teaching so that students will be encouraged and motivated to participate in the learning process.

\section{REFERENCES}

[1] J. S. Jali, "Some factors influencing job satisfaction \& job performance of reading teachers in the division of Iligan City, a proposal training program," Ph.D. dissertation, Dept. Educ., Liceode Cagayan University, Cagayan de Oro City, Philippines, 2000.

[2] G. V. Aquino, Educational Administration: Theory and Practice, Rex Bookstore, Quezon City, 1998.

[3] M. Dizon, "Relationship of stress and the teaching performance of the faculty members of Mindanao State University: basis for continuing professional development program," Ph.D. dissertation, Dept. Educ. Liceo de Cagayan University, Cagayan de Oro City, Philippines, 2005.

[4] M. Jarvis. (July, 2002). Stress News. [Online]. Available: http://www.isna.org.uk/Stressisna/teachersstress.html 
[5] Understanding Stress: Symptoms, Signs, Causes and Effects. (August, 2012). [Online]. Available: http://www. helpguide.org/mental/stress_signs.htm

[6] Briner et al. (July, 2012). Occupational Stress Org. govt. School Teachers: Cause \& Preventive Measures. [Online]. Available: http://www.worksafe.gov.au/biblio/ 0/111939'html

[7] Lardizabal et al., Principles and Methods of Teaching, Phoenix Publishing House, 1998.

[8] Management of Work related Policy. (2012). [Online], Available: http: //www.Surrey.ac.uk

[9] L. Evans, "Teachers morale," Job Satisfaction and Motivation, Great Britain, Paul Chapman, Publishing, Inc., 1998.

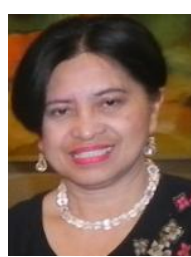

Julieta Remedios Betonio became a member of IAMURE multidisciplinary research in May, 2013 and was born in Ozamiz City, Misamis Occidental, Mindanao, Philippines on July 12, 1955. She finished the degree of bachelor of science in commerce, major in accounting,
1977, bachelor of arts in economics in 1980 and master in business administration - 1995 at Immaculate Conception College-La Salle, Ozamiz City, Philippines. She obtained her doctor in management degree in 2005 at Liceo de Cagayan University, Cagayan de Oro City, Philippines.

She was the student's record evaluator, head of the lady work scholars, coordinator of master of business administration and College of Commerce Department, director, student's financial assistance and scholar ship program, director, human resource, vice chancellor for administration and at present director, for special projects and professor in doctor in business administration (DBA) and College of Business and Economics at La Salle University, Ozamiz City. Her interests in research are in but not limited to human resource, education, social concerns and communication technology.

Dr. Julieta Betonio was also one of the concurrent session managers at the asian conference on multidisciplinary research in higher education 2013 (ACMRHE 2013). She was given gold award as best oral presenter during the world research festival 2013 (WRF2013) in May, 2013 and in asian conference on multidisciplinary research in higher education 2013 (ACMRHE 2013) last November 28, 2013. 